\title{
EDITORIAL NOTE \\ Origin of thickening in monocotyledon stems, slope variation and population structure in a riparian forest, and the influence of seagrass beds in fish community structure
}

\author{
ALEXANDER W. A. KELLNER \\ Editor-in-chief
}

The impact factor of the Anais da Academia Brasileira de Ciências (AABC) has increased significantly over the last years, reaching for the first time a value above one (ISI-Thomson 2009, 1.074). This clearly shows the growing impact of this journal in the development of science worldwide, which is expected to increase further in the years ahead.

Among the interesting studies published in this issue of the AABC that should be highlighted is the work on the primary and secondary thickening in the stem of a monocotyledon species by Marina B. Cattai and Nanuza L. de Menezes from the Instituto de Biociências of the Universidade de São Paulo. There is still great discussion over how this thickening occurs in this major group of flowering plants. The debate on this subject started in the nineteenth century and is nowadays centered in the notion of a "primary thickening meristem" (PTM, for a review see Rudall 1991). Addressing this question, Cattai and Menezes (2010) determined how primary growth takes place in Cordyline fruticosa, also popularly known as cabbage palm, and how it affects the secondary thickening meristem. The authors have essentially based their study on histological cross-sections of specimens original from Asia, collected from the garden of the Instituto de Biociencias.

Still regarding plants, Edmilson Bianchini of the Centro de Ciências Biológicas of the Universidade Estadual de Londrina and colleagues provided new information that can help our understanding of the tree species ecology of what remains from the Atlantic Forest. As several authors have pointed out before, resource availability and divergent associations of habitat have a great influence during regeneration, reflecting wide ranges of vital rates among taxa (e.g., Wright et al. 2003). Bianchini et al. (2010) have studied the size structure and spatial arrangement of 13 different kinds of trees that were abundant in a riparian forest fragment located in the Paraná State. The main purpose of the research was to establish if the size and spatial structures differ among species groups and if the slope was related to the spatial distribution of the species. Their main results indicate that niche differentiation is most likely a fundamental factor with high influence on the way that the tree community is structured.

Moving from land to sea, it has been observed that seagrass beds are used by several species of fishes for protection and food supply. Nonetheless, there is a need to quantify the role these ecosystems play as a refuge for species living in reefs and estuaries (Adams and Ebersole 2002), particularly when these regions are close to heavily populated areas and therefore subject to great influence by human impact. To provide more empirical data on the community structure of the ichthyofauna that makes use of seagrass beds, Pedro Pereira and colleagues of the Departamento de Oceanografia of the Universidade Federal de Pernambuco have investigated the Formoso River estuary situated in the Municipality of Tamandaré at the Pernambuco State. The study area is placed at the limits of two environmental protection areas - Guadalupe and Costa dos Corais (Pereira et al. 2010). With daytime and nighttime manual trawls 
they collected over 350 specimens, all from the Carneiro beach, that includes several ecosystems from mangroves to coral reefs. This kind of study might help policy makers in the difficult tasks to delimit areas and establish rules regarding the urgent conservation of such regions.

\section{REFERENCES}

AdAms AJ AND Ebersole JP. 2002. Use of back-reef lagoon habitats by coral reef fishes. Mar Ecol Prog Ser 228: $213-226$.

Bianchini E, Garcia CC, Pimenta JA And Torezan JMD. 2010. Slope variation and population structure of tree species from different ecological groups in South Brazil. An Acad Bras Cienc 82: 643-652.

Cattai MB And Menezes NL De. 2010. Primary and secondary thickening in the stem of Cordyline fruticosa (Agavaceae). An Acad Bras Cienc 82: 653-662.

Pereira PHC, Ferreira BP And Rezende SM. 2010. Community structure of the ichthyofauna associated with seagrass beds (Halodule wrightii) in Formoso River estuary - Pernambuco, Brazil. An Acad Bras Cienc 82: 617-628.

RUDALL P. 1991. Lateral meristems and stem thickening growth in monocotyledons. Bot Rev 57: 150-163.

Wright SJ, Muller-Landau HC, Condit R And Hubbell SP. 2003. Gap-dependent recruitment, realized vital rates, and size distributions of tropical trees. Ecology 84: 3174-3185. 